07

\title{
Исследование воздействия электронного и протонного облучения на приборные структуры на основе $4 \mathrm{H}$-SiC
}

\author{
(C) А.А. Лебедев ${ }^{1}$, К.С. Давыдовская ${ }^{1}$, А.Н. Якименко ${ }^{2}$, \\ А.М. Стрельчук ${ }^{1}$, В.В. Козловский ${ }^{2}$ \\ ${ }^{1}$ Физико-технический институт им. А.Ф. Иоффе РАН, Санкт-Петербург \\ ${ }^{2}$ Санкт-Петербургский политехнический университет Петра Великого \\ E-mail: shura.lebe@mail.ioffe.ru
}

Поступило в Редакцию 16 июня 2017 г.

Исследовано изменение вольт-амперных характеристик и величины нескомпенсированной донорной примеси $\left(N_{d}-N_{a}\right)$ в базе диодов Шоттки и JBS-диодов на основе $4 H-\mathrm{SiC}$ при их облучении электронами с энергией $0.9 \mathrm{MeV}$ и протонами с энергией $15 \mathrm{MeV}$. Скорость удаления носителей при облучении электронами составила $0.07-0.15 \mathrm{~cm}^{-1}$, а при облучении протонами $50-70 \mathrm{~cm}^{-1}$. Показано, что исследованные приборы сохраняли выпрямляющие вольт-амперные характеристики вплоть до доз электронного облучения $\sim 10^{17} \mathrm{~cm}^{-2}$. Показано, что радиационная стойкость исследованных приборов на основе $\mathrm{SiC}$ существенно превосходит радиационную стойкость кремниевых $p-i-n$-диодов с аналогичными напряжениями пробоя.

DOI: 10.21883/PJTF.2017.22.45262.16921

Ранее было показано, что карбид кремния $(\mathrm{SiC})$ имеет большие перспективы для разработки на его основе приборов высоковольтной и сильноточной электроники [1-3]. В настоящее время на основе $4 \mathrm{H}-\mathrm{SiC}$ осуществляется коммерческий выпуск диодов Шоттки, JBS-диодов и MOSFET-транзисторов. По сравнению с $p-i-n$-диодами на основе кремния SiC-диоды Шоттки обладают большим быстродействием (как прибор на основных носителях заряда) и меньшими обратными токами при комнатной температуре (из-за большей величины запрещенной зоны) при примерно такой же высоте потенциального барьера при прямом напряжении и таком же напряжении пробоя. Первые работы по исследованию радиационных дефектов в карбиде кремния, проведенные в 1950-1960 гг., подтверждали высокую радиационную стойкость этого 
Скорости удаления носителей в приборах на основе $\mathrm{SiC}$ и $\mathrm{Si}$

\begin{tabular}{|c|c|c|c|c|}
\hline Параметр & Дш $600 \mathrm{~V}$ & ДШ $1200 \mathrm{~V}$ & JBS $1700 \mathrm{~V}$ & $\mathrm{Si}$ \\
\hline$N_{d}-N_{a}$ в базе, $\mathrm{cm}^{-3}$ & $6.5 \cdot 10^{15}$ & $4.5 \cdot 10^{15}$ & $3.5 \cdot 10^{15}$ & $\sim 10^{15}$ \\
\hline $\begin{array}{c}V_{d}, \text { электроны } \\
(0.9 \mathrm{MeV}), \mathrm{cm}^{-1}\end{array}$ & $0.095[11]$ & $0.073[11]$ & $0.15^{*}$ & $0.23-2[12]$ \\
\hline $\begin{array}{c}V_{d}, \text { протоны } \\
(15 \mathrm{MeV}) \mathrm{cm}^{-1}\end{array}$ & $63^{*}$ & $50^{*}$ & $54^{*}$ & $110[13]$ \\
\hline
\end{tabular}

* Данные настоящей работы.

материала [4]. Однако в последнее время появились публикации, в которых утверждается, что детекторы на основе $\mathrm{SiC}$ не только не превосходят детекторы на основе кремния по радиационной стойкости, но даже уступают им по ряду параметров [5-8].

Цель настоящей работы состоит в исследовании радиационной стойкости промышленно выпускаемых диодов Шоттки и JBS-диодов на основе $\mathrm{SiC}$ при их облучении электронами с энергией $0.9 \mathrm{MeV}$ и протонами с энергией $15 \mathrm{MeV}$.

В работе исследованы диоды Шоттки (ДШ) на основе $4 \mathrm{H}-\mathrm{SiC}$ производства фирмы CREE (США) [9] с напряжениями пробоя 600 и $1200 \mathrm{~V}$ и JBS-диоды с напряжением пробоя $1700 \mathrm{~V}$. Концентрация нескомпенсированной донорной примеси $\left(N_{d}-N_{a}\right)$ в исходных приборах до облучения составляла $(3.5-6.5) \cdot 10^{15} \mathrm{~cm}^{-3}$.

Облучение электронами с энергией $0.9 \mathrm{MeV}$ проводилось на импульсном ускорителе (resonant transformer accelerator, частота импульсов $490 \mathrm{~Hz}$, длительность импульса $330 \mu \mathrm{s}$ ) на охлаждаемой проточной водой мишени. Пробег электронов с энергией $0.9 \mathrm{MeV}$ составляет $\sim 1.0 \mathrm{~mm}$ в $\mathrm{SiC}$. Средняя плотность тока пучка электронов равна $12.5 \mu \mathrm{A} \cdot \mathrm{cm}^{-2}$. Можно считать, что при электронном облучении дефекты вводились равномерно по объему образцов, поскольку толщина облучаемых образцов $\mathrm{SiC}$ была значительно меньше длины пробега электронов. Максимальная доза облучения составляла $\sim 1.5 \cdot 10^{17} \mathrm{~cm}^{-2}$. Облучение протонами выполнялось на циклотроне МГЦ-20. Использовались протоны с энергией $15 \mathrm{MeV}$ с максимальной дозой облучения $(D) \sim 1.0 \cdot 10^{14} \mathrm{~cm}^{-2}$. 


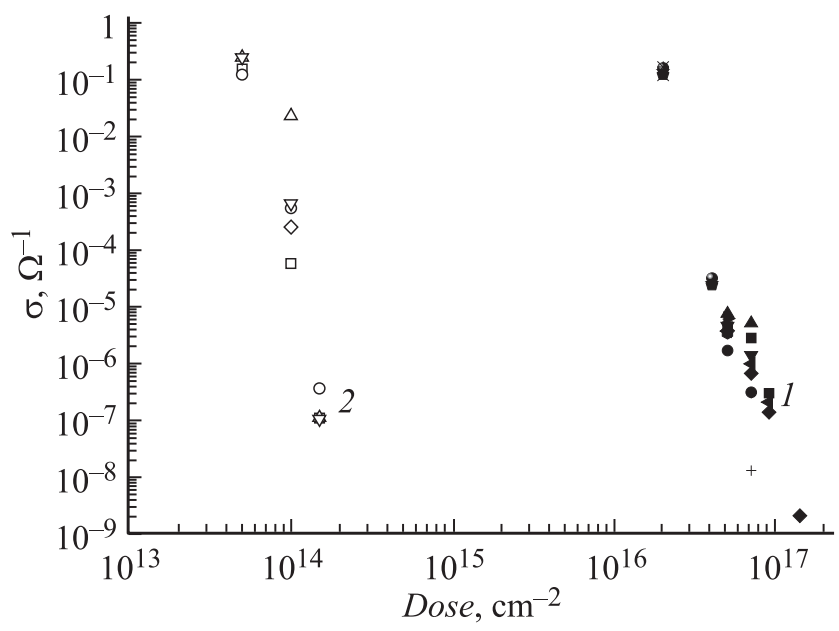

Рис. 1. Зависимость проводимости диодов Шоттки в прямом направлении от дозы облучения электронами (1) и протонами (2).

Скорость удаления носителей рассчитывалась по формуле:

$$
V_{d}=\left(N_{0}-N_{1}\right) / \Delta D,
$$

где $N_{0}-$ концентрация $N_{a}-N_{d}$ в эпитаксиальном слое до облучения; $N_{1}$ - концентрация $N_{a}-N_{d}$ в эпитаксиальном слое после облучения, $\Delta D$ - доза облучения.

Концентрация нескомпенсированных акцепторов $\left(N_{a}-N_{d}\right)$ в исходных и облученных образцах определялась по вольт-фарадным характеристикам $(C-U)$ на стандартной установке с параллельной схемой замещения и синусоидальной частотой $10 \mathrm{kHz}$ при комнатной температуре.

В ходе проведения экспериментов наблюдалось линейное уменьшение концентрации $N_{d}-N_{a}$ для всех типов приборов. Скорость удаления носителей составила $V_{d} \sim 0.095 \mathrm{~cm}^{-1}$ для концентрации в базовой области диода $6.5 \cdot 10^{15} \mathrm{~cm}^{-3}, V_{d} \sim 0.073 \mathrm{~cm}^{-1}$ для концентрации $4.5 \cdot 10^{15} \mathrm{~cm}^{-3}$ и $V_{d} \sim 0.15 \mathrm{~cm}^{-1}$ (JBS-диоды). Эта величина приблизительно в 2 раза ниже, чем для кремния при той же концентрации $N_{d}-N_{a}[10]$ (см. таблицу). Если же провести сравнение с кремниевым $p-i-n$-диодом, имеющим то же напряжение пробоя, то следует брать

5 Письма в ЖТФ, 2017, том 43, вып. 22 


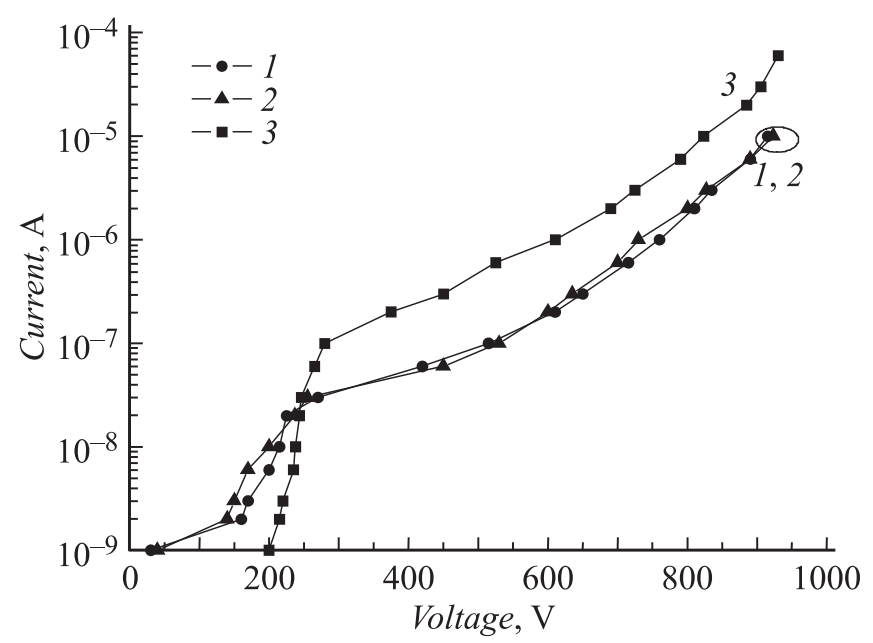

Рис. 2. Обратные BAX двух диодов Шоттки до облучения $(1,2)$ и после облучения протонами с энергией $15 \mathrm{MeV}$ и дозой $1.5 \cdot 10^{14} \mathrm{~cm}^{-2}(3)$.

величину $N_{d}-N_{a}$ на два порядка меньше, чем в $\mathrm{SiC}$, так как критическое поле пробоя в $\mathrm{Si}$ в 10 раз меньше, чем в $\mathrm{SiC}$. Это означает, что для компенсации диода Шоттки на основе $\mathrm{SiC}$ потребуется примерно в 200 раз бо́льшая доза облучения, чем для компенсации кремниевого $p-i-n$-диода с тем же напряжением пробоя.

На рис. 1 представлено изменение проводимости приборов в прямом направлении в зависимости от дозы облучения. На рис. 2 показаны обратные вольт-амперные характеристики (BAX) исследовавшихся приборов в зависимости от дозы облучения. Как видно из рисунков, при дозах облучения более $1 \cdot 10^{16} \mathrm{~cm}^{-2}$ сохраняются выпрямляющие свойства приборов, хотя, согласно данным измерений ВАХ при этих дозах, концентрация $N_{d}-N_{a}$ стремится к нулю. Это связано с тем, что концентрация $N_{d}-N_{a}$ в подложке на три порядка выше, чем в базовой области и использованные дозы облучения не приводят к ее значительной компенсации. В результате после облучения исследовавшиеся приборы приобретают структуру, аналогичную структуре $p-i-n$-диодов. Слой объемного заряда при нулевом напряжении занимает всю базовую область, проводимость которой стремится к собствен-

Письма в ЖТФ, 2017, том 43, вып. 22 
ной. Полный отжиг введенных радиационных дефектов наблюдался при температуре $\sim 1200^{\circ} \mathrm{C}[14]$.

Таким образом, обнаружено, что скорость удаления носителей при облучении приборов на основе $4 H$-SiC с концентрацией нескомпенсированных доноров $N_{d}-N_{a} \sim 4-6 \cdot 10^{15} \mathrm{~cm}^{-3}$ электронами с энергией $0.9 \mathrm{MeV}$ составляет $\sim 0.1 \mathrm{~cm}^{-1}$, а при облучении протонами с

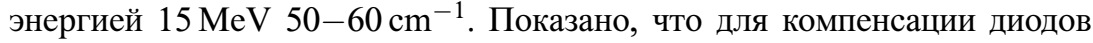
Шоттки на основе $4 H$-SiC потребуется примерно в 200 раз большая доза облучения, чем для кремневых $p-i-n$-диодов с таким же напряжением пробоя.

Работа выполнена при поддержке РНФ (грант № 16-12-10106 „Радиационная стойкость карбида кремния и приборы на его основе для экстремальной электроники“').

\section{Список литературы}

[1] Jonson E.O. // RCA Rev. 1965. V. 26. P. 163-177.

[2] Baliga B.J. // J. Appl. Phys. 1982. V. 53. P. 1759-1764.

[3] Лебедев А.А., Челноков В.Е. // ФТП. 1999. Т. 33. В. 9. С. 1096-1099.

[4] Choyke W.J. // Inst. Phys. Conf. Ser. 1977. V. 31. P. 58-69.

[5] Hallen A., Henry A., Pelligrino P. et al. // Mater. Sci. Eng. B. 1999. V. 61-62. P. 378-381.

[6] Swensson B.G. et al. // Mater. Sci. Forum. 2001. V. 353-356. P. 349-354.

[7] Casse G. // Nucl. Instrum. Meth. Phys. Res. A. 2009. P. 54-60.

[8] Metcalfe J. // Nucl. Phys. B (Proc. Suppl.) 2011. V. 215. P. 151-153.

[9] http://cree.com/

[10] Emtsev V.V., Ivanov A.M., Kozlovski V.V. et al. // ФТП. 2012. Т. 46. В. 4. C. 473481.

[11] Лебедев А.А., Давыдовская К.С., Стрельчук А.М., Козловский В.В.. // Поверхность. Рентгеновские, синхротронные и нейтронные исследования. 2017. № 9. С. 11-13 и др.

[12] Козловский В.В., Емцев В.В., Емцев К.В. и др. // ФТП. 2008. Т. 42. В. 2. C. 243-248.

[13] Kozlovski V.V., Strokan N.B., Ivanov A.M., Lebedev A.A., Emtsev V.V., Oganesyan G.A., Poloskin D.S. // Physica B. 2009. V. 404. P. 4752.

[14] Лебедев А.А., Богданова Е.В., Григорьева М.В., Лебедев С.П., Козловский В.В. // Письма в ЖТФ. 2012. Т. 38. В. 19. Р. 90-94.

5* Письма в ЖТФ, 2017, том 43, вып. 22 